\title{
Conquering Metastatic Breast Cancer
}

Nancy E. Davidson, MD

University of Pittsburgh Cancer Institute and UPMC Cancer Center, Pittsburgh, PA

\section{ASSOCIATED CONTENT}

See accompanying article on page 6

DOl: 10.1200/JOP.2015.009167
The plight of women (and men) with metastatic breast cancer and our wish to improve on our current inability to effect long-term cures for these patients are in our thoughts. Metastatic breast cancer is the top cancer killer for US women younger than 54 years of age, and some 40,000 individuals succumb each year in the United States, accounting for many lost years of productive life. ${ }^{1}$

The accompanying article by Sledge ${ }^{2}$ outlines an ambitious and rational plan for seeking a cure for a larger population of patients with metastatic disease. It is informed by our enhanced understanding of the biology of breast cancer during the past several decades that has led to a number of advances, both technologic (panomics, detection of cell-free DNA, circulating tumor cell detection, more sensitive imaging, etc) and therapeutic (targeted agents and immunotherapy), that might be reasonable to harness to pursue the elusive goal of cure. Indeed the research agenda for curing metastatic breast cancer presented in Table 2 of the article by Sledge ${ }^{2}$ is a laudable one for many types of advanced-stage epithelial cancers. One major gap in breast cancer is the relative paucity of molecular profiling of metastatic breast cancer lesions, and this void is beginning to be addressed through initiatives like the AURORA projects in the United States and Europe. ${ }^{3}$

But as we contemplate this agenda, let us not neglect the best form of treatment of metastatic breast cancer, namely prevention of the disease altogether coupled with effective detection and treatment of breast cancer in a premetastatic stage. Recently Vogelstein and Kinzler ${ }^{4}$ have suggested that tumors evolve in three broad phases. Cells acquire a driver gene mutation and begin to proliferate abnormally during a lengthy breakthrough phase. This is followed by an expansion phase that is driven by a second driver gene mutation that enables the cells to thrive in a hostile local environment; this phase is dependent on both mutation rate and number of cells at risk. Resulting benign tumors are then subject to acquisition of additional driver gene mutations that enable the third phase, that of local invasion. In this framework it appears likely that invasive cancer cells already have the capacity to metastasize without a fourth driver mutation in many cases. This sequential model has been best credentialed in diseases like colon, pancreatic, and cervical cancers and melanoma, but it seems likely that some variant characterizes many breast cancers as well.

\section{Intervention Opportunities}

This lengthy process provides several opportunities for intervention. Foremost is the possibility for prevention. Though we would not wish to turn back the clock on many of the lifestyle changes that women have embraced over the past century, we should be champions for key interventions like maintaining a normal body mass index and avoidance of excess alcohol or prolonged hormone replacement therapy. Chemoprevention for breast cancer with selective estrogen receptor modulators or aromatase inhibitors is an underused and evidence-based approach. ${ }^{5}$ The ability 
to identify high-risk individuals with germline mutations in $B R C A 1$ or $B R C A 2$ or other key DNA repair genes is now readily available, affording these women the opportunity to undertake preventive surgery. ${ }^{6}$

It seems certain that early detection by mammography will also continue to be key for the foreseeable future, despite concerns that the incidence of de novo metastatic breast cancer has not decreased during the era of mammographic screening. ${ }^{7}$ Opportunities to develop adjunctive early detection methods on the basis of panomic analysis of biospecimens or alternative imaging strategies will continue to grow and require rigorous evaluation.

The lessons of four decades of adjuvant systemic therapy with biomarker-driven use of endocrine and anti-HER2-based therapies should also be extended to other targeted therapies as they emerge in the breast cancer space. The need to pair target identification with targeted agent is paramount as we compare the success of these therapies with our failure with antiangiogenic approaches in breast cancer to date. Ideally many patients would be exceptional responders in the adjuvant setting and never suffer from overt metastatic disease as a result.

Finally, we should not forget the importance of implementing what we already know today. Think about the potential impact of the uniform application of a simple intervention of 5 years of adjuvant tamoxifen and/or aromatase inhibitor for women with early-stage hormone receptorpositive breast cancer. ${ }^{8}$ The need for informed physicians to make the right recommendations is vital and ever more challenging in the era of precision cancer medicine. The imperative for us to promote patient adherence to our recommendations is just as great as is our obligation to reduce disparities in provision of state-of-the-art care across our population.
Pursuing a research agenda to increase the cure rate for metastatic breast cancer is a worthwhile aspirational goal, and such work is underway. But in this quest let us not forget that an ounce of prevention of breast cancer metastasis-by a threepronged approach of prevention, early detection, and effective local and adjuvant systemic therapy — is likely to be worth a pound of cure. JoP

\section{Acknowledgment}

Commentary partially supported by National Institutes of Health Grant No. P30 CA047904 and the Breast Cancer Research Foundation.

\section{Author's Disclosures of Potential Conflicts of Interest}

Disclosures provided by the author are available with this article at jop.ascopubs.org.

Corresponding author: Nancy E. Davidson, MD, University of Pittsburgh Medical Center, Cancer Pavilion, 5150 Centre Ave, Suite 500, Pittsburgh, PA 15232; e-mail: davidsonne@upmc.edu.

\section{References}

1. Siegel RL, Miller KD, Jemal A: Cancer statistics. CA Cancer J Clin 65:5-29, 2015 2. Sledge GW Jr: Curing metastatic breast cancer. J Oncol Pract 12:6-10, 2016

3. Zardavas D, Maetens M, Irrthum A, et al: The AURORA initiative for metastatic breast cancer. Br J Cancer 111:1881-1887, 2014

4. Vogelstein B, Kinzler KW: The path to cancer-Three strikes and you're out. N Engl J Med 373:1895-1898, 2015

5. Visvanathan K, Hurley P, Bantug E, et al: Use of pharmacologic interventions for breast cancer risk reduction: American Society of Clinical Oncology clinical practice guideline. J Clin Oncol 31:2942-2962, 2013

6. Domchek SM, Friebel TM, Singer CF, et al: Association of risk-reducing surgery in BRCA1 or BRCA2 mutation carriers with cancer risk and mortality. JAMA 304: 967-975, 2010

7. Welch HG, Gorski DH, Albertsen PC: Trends in metastatic breast and prostate cancer-Lessons in cancer dynamics. N Engl J Med 373:1685-1687, 2015

8. Dowsett M, Forbes JF, Bradley R, et al: Early Breast Cancer Trialists' Collaborative Group (EBCTCG): Aromatase inhibitors versus tamoxifen in early breast cancer: Patient-level meta-analysis of the randomised trials. Lancet 386:1341-1352, 2015 


\section{AUTHOR'S DISCLOSURES OF POTENTIAL CONFLICTS OF INTEREST}

\section{Conquering Metastatic Breast Cancer}

The following represents disclosure information provided by authors of this manuscript. All relationships are considered compensated. Relationships are self-held unless noted. I = Immediate Family Member, Inst = My Institution. Relationships may not relate to the subject matter of this manuscript. For more information about ASCO's conflict of interest policy, please refer to www.asco.org/rwc or jop.ascopubs.org/site/misc/ifc.xhtml.

\section{Nancy E. Davidson}

No relationship to disclose 